\title{
Morphokinetic Analysis of Preimplantation Development of Mouse Oocytes Fertilised in Vitro Using a Non-humidifying Incubator With Time-lapse Cinematography (CCM-iBIS)
}

Hiroyuki Watanabe

Obihiro University of Agriculture and Veterinary Medicine

Haruka Ito

Obihiro University of Agriculture and Veterinary Medicine

Ayumi Shintome

Obihiro University of Agriculture and Veterinary Medicine

Hiroshi Suzuki ( $\square$ hisuzuki@obihiro.ac.jp)

Obihiro University of Agriculture and Veterinary Medicine

\section{Research Article}

Keywords: cinematography, mouse oocytes, in vitro, Preimplantation development, CCM-iBIS

Posted Date: January 11th, 2021

DOl: https://doi.org/10.21203/rs.3.rs-142391/v1

License: (c) (i) This work is licensed under a Creative Commons Attribution 4.0 International License.

Read Full License 
1 Morphokinetic analysis of preimplantation development of mouse oocytes fertilised in vitro using

2 a non-humidifying incubator with time-lapse cinematography (CCM-iBIS)

3

4 Hiroyuki Watanabe, Haruka Ito, Ayumi Shintome, Hiroshi Suzuki*

5

6 Obihiro University of Agriculture and Veterinary Medicine, Inada, Obihiro 080-8555, Japan

7

$8 *$ Correspondence: Obihiro University of Agriculture and Veterinary Medicine, Nishi 2-13,

9 Inada, Obihiro 080-8555, Japan

$10 \quad$ Tel: +81 15549 5640; Fax: +81 15549 5643;

11 E-mail: hisuzuki@obihiro.ac.jp 
1 Abstract

2 Preimplantation development of mouse oocytes fertilised in vitro was assessed in a non-

3 humidified incubator with time-lapse cinematography (CCM-iBIS). The developmental rates of

4 embryos to the 4-cell and blastocyst stages under $5 \% \mathrm{CO}_{2}, 5 \% \mathrm{O}_{2}$, and $90 \% \mathrm{~N}_{2}$ in CCM-iBIS

5 were significantly higher than those under $5 \% \mathrm{CO}_{2}$ in air in $\mathrm{CCM}$-iBIS and a conventional $\mathrm{CO}_{2}$

6 incubator $\left(\mathrm{CPO}_{2}-2301\right)$. The developmental speed of embryos was much faster in those cultured

7 under lower oxygen tension in CCM-iBIS than in higher oxygen tension in CCM-iBIS and $\mathrm{CPO}_{2}-$

8 2301. Embryonic development was much faster and more synchronised under lower oxygen

9 tension. Non-humidified culture did not affect the development of the embryos. Mouse embryos

10 cultured at lower oxygen tension reached 2-cell at $17 \mathrm{~h}, 3$-cell at $39 \mathrm{~h}, 4$-cell at $40 \mathrm{~h}$, initiation of

11 compaction at $58 \mathrm{~h}$, morula at $70 \mathrm{~h}$, and blastocyst at $82 \mathrm{~h}$ after insemination on average. Although

12 compaction partially unravelled with cell division in compacting embryos, it appeared to

13 complete depending on the timing of observation. Observation at a conventional 24-h interval

14 likely misjudges the developmental rate to morula. Determination of embryonic development 72

$15 \mathrm{~h}$ after insemination may be more appropriate for "compacting morula" rather than "morula" in

16 mice. 


\section{Introduction}

Since the first successful in vitro fertilisation (IVF) of mice in 1968 using uterine spermatozoa collected after mating [1], components of culture medium as well as procedures of IVF have been substantially modified and improved. In 1969, successful mouse IVF with epididymal spermatozoa in the presence of bovine follicular fluid was reported by Iwamatsu and Chang [2]. In 1971, Toyoda et al. [3] established an IVF method for mouse eggs with epididymal spermatozoa in a modified Krebs-Ringer bicarbonate solution supplemented with glucose, Napyruvate, and bovine serum albumin (BSA) with higher fertilisation rates and reproducibility. This study demonstrated that mouse spermatozoa can be capacitated in vitro in a chemically defined medium (TYH) without the necessity of fluids from the female reproductive tract. To date, TYH medium has been extensively used as a standard medium for IVF in mice as well as other species of mammals.

Fertilised mouse eggs derived from certain inbred strains or F1 hybrids can be cultured throughout the preimplantation period in a modified Krebs-Ringer bicarbonate solution supplemented with glucose, Na-pyruvate, Na-lactate, and BSA in vitro; however, the majority derived from random bred strains, such as ICR, arrested their development at the two-cell stage [4]. This phenomenon, called in vitro two-cell block, can be overcome by the addition of EDTA$2 \mathrm{Na}$ to the culture medium [5-7]. In addition, the development of normal progeny has been 
confirmed by the subsequent transfer of IVF embryos cultured throughout the preimplantation stage in Whitten medium [4] supplemented with EDTA-2Na [8]. Subsequently, culture media for mouse preimplantation development of embryos have been developed. Chatot et al. [9] developed Chatot, Ziomek, and Bavister (CZB) medium containing an increased lactate/pyruvate ratio, EDTA, and glutamine but lacking glucose and phosphate. Fertilised mouse eggs could develop beyond the 2-cell stage and reach the morula but not the blastocyst stage when cultured in CZB medium. However, washing embryos in the medium containing glucose after $48 \mathrm{~h}$ of culture is sufficient to allow development to the blastocyst stage [9]. The presence of glucose in CZB medium was only necessary from the 4-cell stage and detrimental to earlier stages of embryos in mice. Subsequently, the components of CZB were modified by sequential simplex optimisation methods to design a medium (SOM) that overcomes the two-cell block in an outbred strain of mouse [10]. A modification of the SOM medium, designated KSOM, with an increased concentration of potassium supported development beyond the 2-cell stage and provided a larger yield of blastocysts in an outbred strain of mouse $[11,12]$. Moreover, KSOM was further modified to $\mathrm{mKSOM}^{\mathrm{AA}}$ with an increased concentration of glucose and the addition of 19 amino acids [13]. Culture conditions, such as temperature and atmosphere, may also be important factors for successful preimplantation development of embryos in vitro as well as in culture media. To culture mouse embryos in vitro, an atmosphere of $5 \% \mathrm{CO}_{2}$ in air with a saturated humidity at $37{ }^{\circ} \mathrm{C}$ in an 
1 incubator is typically used. Furthermore, a small droplet of medium containing embryos on a dish

2 is covered with paraffin oil to avoid releasing $\mathrm{CO}_{2}$ from the medium and evaporation and

3 contamination of the medium for manipulation or observation of embryos outside of the $\mathrm{CO}_{2}$

4 incubator [14]. Morphological observation of developing embryos seems to be essential for

5 managing and/or improving culture conditions in experimental and clinical studies. However,

6 frequent opening and shutting of the $\mathrm{CO}_{2}$ incubator for microscopic observation of culturing

7 embryos might disturb the culture conditions. Therefore, it is necessary to reduce the frequency

8 of observation of culturing embryos for successful preimplantation development in a $\mathrm{CO}_{2}$

9 incubator. Such fragmentary information may provide a limited analysis of developing embryos.

10 Fortunately, it has become possible to consecutively observe culturing embryos in vitro via time-

11 lapse video cinematography developed by Payne et al. [15]. $\mathrm{A} \mathrm{CO}_{2}$ incubator equipped with a time-lapse monitoring system is a closed system of culture and observation for embryos without

13 exposure to the atmosphere. Therefore, it can provide stable culture conditions without stress or

14 disturbance. Time-lapse observation has also advanced our understanding of the morphologic mechanisms of the fertilisation, development, and behaviour of early embryos during the

16 preimplantation period. Therefore, the automatic capture of time-lapse images would provide useful

17 information for embryo selection for subsequent embryo transfer. Previous studies have investigated

18 pronuclear formation [15, 16], timing of cleavage [16, 17], fragmentation [18-21], compaction 
1 [22-27], blastocoel formation [26, 28], and the shape of the inner cell mass [29] in human

2 zygotes/embryos using a time-lapse monitoring system. Embryos that cleave early at the first

3 cleavage have a higher potential for subsequent pre- and post-implantation development [17, 30-

4 32]. Therefore, the timing of the first zygotic cleavage appears to be a marker of the

5 developmental potential of mammalian embryos. Furthermore, the culture of human embryos in

6 an incubator with a time-lapse monitoring system may improve development to the blastocyst

7 stage and pregnancy outcomes compared to the use of a conventional $\mathrm{CO}_{2}$ incubator $[33,34]$.

8 Initially, this system was only applied for assisted reproductive technology in human

9 infertility treatment due to the high-priced system for introduction. Recently, a time-lapse

10 monitoring system has been applied for the evaluation of mouse embryonic development in vitro.

11 The first and second cleavage of mouse oocytes fertilised in vivo significantly influences the

12 probability of reaching the blastocyst stage in culture [35]. The shorter the time of cleavage to the

13 2-cell stage and from the 2-cell to 3-cell stage, the higher is the chance of embryo development

14 to the blastocyst stage [35]. When the time of cleavage and compaction of mouse 2-cell embryos

15 fertilised in vivo was evaluated by time-lapse monitoring, it was suggested that the time of the

16 third cleavage and compaction may be a useful morphokinetic parameter for predicting

17 developmental potential [36]. Prior to these studies, by using time-lapse film cinematography,

18 Sutherland et al. [37] were able, for the first time, to directly examine the division plane of 8-cell 
1 blastomeres during the fourth cleavage of mouse embryos cultured from the late 2-cell stage.

2 Since these studies in mice used embryos fertilised in vivo, in the present study,

3 preimplantation development of mouse oocytes fertilised in vitro was assessed. This was

4 conducted in a non-humidified incubator with time-lapse cinematography, and the sperm

5 penetration time was accurately controlled in the IVF system $[3,8,38]$ to evaluate morphokinetic

6 development with higher precision. 


\section{$1 \quad$ Results}

2 Results of the in vitro cultivation and fertilisation of mouse embryos in a non-humidifying

3 incubator with time-lapse cinematography (CCM-iBIS) are shown in Table 1. The developmental

4 rates of embryos to the 4-cell stage $48 \mathrm{~h}$ after insemination cultured in $5 \% \mathrm{CO}_{2}, 5 \% \mathrm{O}_{2}$, and $90 \%$

$5 \mathrm{~N}_{2}$, and $5 \% \mathrm{CO}_{2}$ in air in CCM-iBIS, and $5 \% \mathrm{CO}_{2}$ in air under a humidified atmosphere in a

6 conventional $\mathrm{CO}_{2}$ incubator $\left(\mathrm{CPO}_{2}-2301\right)$ were $97 \%(288 / 297), 89 \%$ (845/951), and 79\%

7 (79/100), respectively. The differences between the three experimental groups were significantly

8 different at $\mathrm{P}<0.05$. The developmental rates of embryos to morula $72 \mathrm{~h}$ after insemination in

9 lower and higher oxygen tension in CCM-iBIS were $72 \%(215 / 297)$ and $62 \%(588 / 951)$,

10 respectively. This difference was statistically significant at $\mathrm{P}<0.05$. Developmental rates to the

11 blastocyst stage at $96 \mathrm{~h}(94 \% ; 280 / 297)$ and $120 \mathrm{~h}(97 \% ; 288 / 297)$ after insemination under lower

oxygen tension in CCM-iBIS were significantly higher $(\mathrm{P}<0.05)$ than those in higher oxygen

tension in CCM-iBIS (77\%; 733/951 and 88\%; 835/951) and higher oxygen tension in $\mathrm{CPO}_{2}$ -

$142301(84 \% ; 84 / 100$ and $86 \% ; 86 / 100)$. However, there were no differences in developmental rates

to the 2 -cell stage $24 \mathrm{~h}$ after insemination between the three experimental groups. These results

16 indicated that CCM-iBIS with lower oxygen tension better supported embryonic development

17 after the 4-cell stage in mice. Table 2 shows the developmental stage of embryos every $24 \mathrm{~h}$ after

18 insemination in CCM-iBIS and $\mathrm{CPO}_{2}-2301$. Then, $48 \mathrm{~h}$ after insemination, $38 \%$ of embryos 
1 developed beyond the 4-cell stage to the 5-cell stage in CCM-iBIS with lower oxygen tension.

2 Only $10 \%$ and $4 \%$ of embryos showed the 5-cell stage in CCM-iBIS with higher oxygen tension

3 and $\mathrm{CPO}_{2}-2301$, respectively. Then, $72 \mathrm{~h}$ after insemination, $74 \%$ and $67 \%$ of embryos with

4 compaction reached completion as morula in CCM-iBIS with lower and higher oxygen tension,

5 respectively. Similarly, $96 \mathrm{~h}$ after insemination, $96 \%$ of embryos developed beyond the blastocyst

6 stage to expanded or hatching blastocysts in CCM-iBIS with lower oxygen tension. However,

7 only $64 \%$ and $33 \%$ of embryos showed expanded blastocysts or hatching blastocysts in CCM-

8 iBIS with higher oxygen tension and $\mathrm{CPO}_{2}-2301$, respectively. For $\mathrm{CCM}-\mathrm{iBIS}$ and $\mathrm{CPO}_{2}-2301$,

9 both with higher oxygen tension, embryos cultured in CCM-iBIS showed a more advanced

10 embryonic stage. For example, $58 \%$ of embryos showed hatching blastocysts in CCM-iBIS, while

11 hatching blastocysts were only 5\% in $\mathrm{CPO}_{2}-230196 \mathrm{~h}$ after insemination.

As shown in Table 3, when the average attainment time after insemination to each developmental stage was analysed by time-lapse cinematography, culture of in vitro fertilised

eggs in lower oxygen tension improved embryonic development from the 2-cell stage throughout preimplantation development. Namely, the IVF embryos cultured in lower oxygen tension

16 developed significantly earlier throughout preimplantation development, except for development

17 to the morula stage, than in higher oxygen tension $(\mathrm{P}<0.05)$. These results indicate that oxygen

18 tension in culture is an important factor for the developmental potential of mouse embryos 
1 fertilised in vitro. Fig. 1 shows a histogram of the number of IVF embryos at each developmental

2 stage with the time lapse after insemination. Despite oxygen tension, the time of onset of cleavage

3 was similar at each developmental stage. On the other hand, it took a considerable amount of time

4 to cleave after the second cleavage ( $\mathrm{t} 3$ ) in some embryos cultured under higher oxygen tension.

5 The cleavage and development of IVF embryos were much faster and more synchronised in lower

6 oxygen tension than in higher oxygen tension in CCM-iBIS.

To assess the influence of non-humidified culture conditions on embryonic development in vitro, embryos were cultured under higher oxygen tension in a conventional incubator $\left(\mathrm{CPO}_{2}-\right.$ 2301) without opening or closing the incubator door from the start of culture to the time of observation. Developmental rates of IVF embryos to the 4-cell stage $48 \mathrm{~h}$ after insemination and

11 to the blastocyst stage $96 \mathrm{~h}$ after insemination were $84 \%(42 / 50)$ and $82 \%(41 / 50)$, respectively

12 (Table 4). These values are not significantly different to those of the developmental rates of

13 fertilised eggs to the 4-cell stage at $48 \mathrm{~h}(89 \%)$ and to the blastocyst stage at $96 \mathrm{~h}(77 \%)$ after

14 insemination under higher oxygen tension in the non-humidifying incubator with time-lapse cinematography (CCM-iBIS). These results indicated that non-humidified culture conditions did

16 not affect the development of mouse IVF embryos.

17 Fig. 2 illustrates the progression of cleavage of the IVF eggs cultured in lower oxygen 18 tension in CCM-iBIS. The first cleavage occurred $17 \mathrm{~h} 27 \mathrm{~min}$ after insemination. The second 
1 cleavage was initiated at $38 \mathrm{~h} 39$ min after insemination. The time between the first and second

2 cleavages was $21 \mathrm{~h} 12 \mathrm{~min}$. The 3 -cell stage was performed for $0 \mathrm{~h} 58 \mathrm{~min}$. The second cleavage

3 was completed 39 h 37 min after insemination. At 9 h 25 min after the second cleavage, the third

4 cleavage was initiated; specifically, 49 h 2 min after insemination. The compaction of embryos

5 was initiated $57 \mathrm{~h} 39$ min after insemination and reached morula $70 \mathrm{~h} 0 \mathrm{~min}$ after insemination.

6 Interestingly, compacting embryos during development to morula showed a phenomenon in

7 which compaction was loosened due to an increase in the number of blastomeres accompanying

8 cell division. Morula developed into blastocysts at 12 h 20 min; specifically, 82 h 20 min after

9 insemination.

10 When the relationship between attainment time to 2-, 3-, 4-, and 5-cell as well as initiation

11 of compaction and morula and attainment time to blastocyst stage was analysed, the correlation

12 coefficients were identified as $\mathrm{r}=0.5016,0.6613,0.6329,0.7087,0.5116$, and 0.4754 ,

13 respectively. Therefore, there were significant correlations between the attainment time to the 2-

14 cell to the morula stage and the attainment time to the blastocyst stage $(\mathrm{P}<0.05)$. The relationship

15 between the attainment times of embryos cultured under higher oxygen tension was similar to

16 those under lower oxygen tension (Fig. 3).

17 
1

2

3

4

5

6

7

8

9

\section{Discussion}

As shown in Tables 1 to 3, the developmental speed of mouse embryos fertilised in vitro was much faster in embryos cultured under lower oxygen tension in CCM-iBIS than in those cultured under higher oxygen tension in $\mathrm{CPO}_{2}-2301$ and $\mathrm{CCM}-\mathrm{iBIS}$. For infertility treatment in humans, the application of time-lapse monitoring together with an embryo-evaluating algorithm is associated with a significantly higher ongoing pregnancy rate, a significantly lower early pregnancy loss, and a significantly higher live birth rate $[33,34,39,40]$. Therefore, the incubator with time-lapse cinematography appears to provide qualitative improvement of embryos in culture for both mice and humans. There are possible explanations for this improved embryonic development as follows: 1) non-humidifying incubation and 2) minimal handling of culturing embryos inside and outside the incubator.

Non-humidified culture conditions did not appear to influence the development of mouse embryos fertilised in vitro (Table 4). Developmental rates of mouse embryos from the 2-cell to blastocyst stage for $96 \mathrm{~h}$ in culture are not significantly different between humidifying and nonhumidifying incubators [41]. Regarding the influence of handling embryos inside and outside the incubator, although there was no difference in the developmental rate to blastocyst stage between the $\mathrm{CCM}$-iBIS and $\mathrm{CPO}_{2}-2301$ incubators with higher oxygen tension, the embryonic development to the 4-cell stage at higher oxygen tension in CCM-iBIS was significantly higher 
1 than that in $\mathrm{CPO}_{2}-2301$ (Table 1). In addition, embryos cultured in CCM-iBIS showed a more

2 advanced embryonic stage $96 \mathrm{~h}$ after insemination (Table 2). When embryos were cultured in

$3 \mathrm{CPO}_{2}-2301$ without opening or closing the incubator door from the start of cultivation to the time

4 of microscopic observation, the developmental rates of embryos were not different from those

5 cultured under higher oxygen tension in CCM-iBIS (Table 4). Therefore, the handling of embryos

6 inside and outside the incubator as well as oxygen tension in the atmosphere in culture appears to

7 influence the cleavage and development of embryos fertilised in vitro. The development of

8 embryos was much faster and more synchronised under lower oxygen tension in culture (Tables

9 1-3 and Fig.1). In this study, we assessed the true effect of oxygen tension on embryonic

10 development in vitro using a time-lapse incubator that does not require the culture dish to be

11 frequently removed to observe the embryos.

Although Sutherland et al. [37], Karnaukhov et al. [42], Pribenszky et al. [35], and Kim et

13 al. [36] applied a time-lapse monitoring system to evaluate mouse embryonic development in

14 vitro, they used zygotes or 2-cell stage embryos derived from fertilisation in vivo. For the evaluation of preimplantation development in vitro with higher precision, analysis of in vitro

16 fertilised eggs with synchronous ovulation and fertilisation is recommended [3,38]. In this study,

17 we precisely showed the timing of cleavage in IVF mouse embryos during preimplantation

18 development through time-lapse cinematography (Tables 2 and 3, Figs. 1 and 2). As shown in Fig. 
12 , when IVF mouse zygotes were cultured in lower oxygen tension, they developed to 2-cell, 4-

2 cell, morula, and blastocyst stages at approximately $17,40,70$, and $82 \mathrm{~h}$ after insemination,

3 respectively. Compaction, where all blastomeres flatten against each other eliminating the spaces

4 between the cells, of embryos was initiated at an average of $57 \mathrm{~h} 39 \mathrm{~min}$ after insemination.

5 Subsequently, the compaction partially unravelled with cleavage of embryos; in other words, with

6 an increase in the number of blastomeres (Fig. 2) [43]. Cell division gives rise to two daughter

7 cells that localise as one internal and one external cell or remain as two external cells with regards

8 to the embryo. Therefore, when the daughter cells are localised externally to the embryo,

9 compaction appears to be loose and incomplete. However, depending on the timing of observation,

10 when the daughter cells are localized as one internal and one external cell, compaction appears to

11 be complete. Although the embryos formed morula with full compaction at an average of $70 \mathrm{~h}$

12 after insemination (Table 3 and Fig. 2), approximately 30\% of embryos did not fully compact at

$1372 \mathrm{~h}$ after insemination (Fig. 1). Therefore, it is likely that a conventional 24-h interval misjudges

14 the developmental rate to morula. When the embryonic development of IVF mouse embryos was

15 observed, the developmental rates to the 2-cell stage $24 \mathrm{~h}$ after insemination, 4-cell stage $48 \mathrm{~h}$

16 after insemination, morula $72 \mathrm{~h}$ after insemination, and blastocysts 96 and $120 \mathrm{~h}$ after

17 insemination were used as an index. However, the determination of embryonic development $72 \mathrm{~h}$

18 after insemination might be more appropriate for the "compacting morula" rather than the "morula" 
1 in mice. Although previous studies have observed compaction and subsequent embryonic

2 development using time-lapse technology in human embryos, these focused on vacuolization in

3 blastomeres [24], timing of morula formation [22, 23, 25, 26], and patterns of compaction with

4 or without extruded blastomeres [22, 27]. There have been, to our knowledge, no previous studies

5 involving the observation of a temporary loosening of compaction during the formation of morula

6 beginning with the initiation of compaction in human embryos [44].

7 In the present study, the attainment time of the first, second, and third cleavage and

8 compaction was correlated with the probability of reaching the blastocyst stage, which is similar

9 to the results of previous studies that used embryos fertilised in vivo $[35,36]$.

10 Procedures of oocyte collection and insemination, culture medium, and culture conditions

11 are key to the success or failure of IVF and subsequent embryo transfer, but the accurate

12 monitoring of embryonic development in vitro is also an important element. Over time,

13 improvements have been made to the IVF method [1-3] and culture medium [3, 5, 8-13] making

14 it possible to obtain stable and highly reproducible results. In addition, the advent of culture

15 conditions, in particular the non-humidifying incubator with time-lapse cinematography [15],

16 allows accurate monitoring of embryonic development in vitro. In particular, as a relatively long

17 period of monitoring is required to accurately determine development to the morula stage, the

18 incubator with time-lapse cinematography appears to function effectively. There is increasing 
1 evidence that early cleavage blastomeres show bias to their development. Blastomeres at the 2-

2 cell stage have an unequal distribution of mitochondrial ribosomal RNAs [45]. Some epigenetic

3 regulators, such as Prdm14, Dnmt3b, and Dnmt31 [46], and cell fate regulator SOX21 [47] are

4 highly heterogeneously expressed between blastomeres of the 4-cell embryo. As shown in Table

53 , in vitro fertilised eggs of mice underwent a first cleavage at $17-18 \mathrm{~h}$ and a second cleavage at

$6 \quad 39-40 \mathrm{~h}$ on average after insemination. However, in the first cleavage, all eggs were in the 2-cell

7 stage $9-11 \mathrm{~h}$ after the first egg was in the 2-cell stage. In the second cleavage, it took $15 \mathrm{~h}$ under

8 lower oxygen tension and $33 \mathrm{~h}$ under higher oxygen tension for all eggs to reach the 3 -cell stage

9 after the first egg was in the 3-cell stage (Fig. 1). Single-cell sequencing and live-cell tracking

10 technology in combination with time-lapse cinematography provides the opportunity to

11 understand the significance of cleavage speed for developmental competency of the embryo.

12 


\section{Materials and Methods}

ICR (CLEA, Japan) female mice at 8-14 weeks of age had superovulation induced by intraperitoneal injections of $175 \mu \mathrm{L}$ of CARD Hyper Ova (Kyudo Co. Ltd., Japan) and 5 i.u. of hCG (ASKA Pharmaceutical Co., Japan) $48 \mathrm{~h}$ apart. These female mice were euthanised by cervical dislocation $16 \mathrm{~h}$ after hCG injection, and the oviducts were removed and placed in a culture dish (35 mm, Falcon, Corning Incorporated, NY, USA) containing $400 \mu \mathrm{L}$ of TYH (LSI Medience Corporation, Japan) covered with paraffin oil (Nacalai Tesque, Japan). The ampullar region of the oviduct was dissected with a needle, and the eggs surrounded by cumulus cells were introduced to the medium. Spermatozoa were collected from the cauda epididymis of ICR males at 18-26 weeks of age and suspended in $400 \mu \mathrm{L}$ of TYH under paraffin oil. After preincubation for $2 \mathrm{~h}$ in an incubator $\left(\mathrm{CPO}_{2}-2301\right.$, HIRASAWA WORKS Inc., Japan) at $37^{\circ} \mathrm{C}$ in humidified $5 \%$ $\mathrm{CO}_{2}$ in air, a small volume of sperm suspension was added to the medium containing eggs. The final concentration of spermatozoa was adjusted to $150 \mathrm{cells} / \mu \mathrm{L}$. Then, $7 \mathrm{~h}$ after insemination, the eggs were transferred into $80 \mu \mathrm{L}$ of KSOM medium supplemented with amino acids (KSOM, Ark Resource, Japan) covered with paraffin oil and washed twice. All media were equilibrated overnight at $37^{\circ} \mathrm{C}$ in humidified $5 \% \mathrm{CO}_{2}$ in air prior to use. After confirmation of the presence of the second polar body and both male and female pronuclei, the fertilised eggs were cultured for $113 \mathrm{~h}$ in a culture dish (LinKID micro DH-004PG, DNP, Japan) containing $60 \mu \mathrm{L}$ of KSOM 
1 covered with paraffin oil at $37^{\circ} \mathrm{C}$ in $5 \% \mathrm{CO}_{2}$ in air (higher oxygen tension) or $5 \% \mathrm{CO}_{2}, 5 \% \mathrm{O}_{2}$,

2 and $90 \% \quad \mathrm{~N}_{2}$ (lower oxygen tension) in a non-humidifying incubator with time-lapse

3 cinematography (CCM-iBIS, ASTEC Co., Ltd., Japan). The CCM-iBIS had a non-humidifying

4 system and was equipped with a 130 million-pixel CCD camera with a $10 \times$ objective lens, red

5 LED lighting, silicone rubber heater with digital PID control, duty controlled gas pressure, and

6 NAS image storage method. The CCD camera for the time-lapse microscope was set to acquire a

7 single image every 15 min. Parameters regarding embryonic development were annotated as

8 follows: $\mathrm{t} 2$, time of cleavage to 2-cell stage after insemination; $\mathrm{t} 3$, time of cleavage to 3 -cell stage

9 after insemination; $\mathrm{t} 4$, time of cleavage to 4-cell stage after insemination; $\mathrm{t} 5$, time of cleavage to

10 5-cell stage after insemination; tOC, time of the onset of compaction after insemination; tM, time

11 of formation of fully compacted morula after insemination; $\mathrm{tB}$, time of blastocyst formation with

12 blastocoel at half volume of embryo after insemination; $\mathrm{tExB}$, time of formation of expanded

13 blastocyst developed to over $120 \mu \mathrm{m}$ in diameter after insemination; tHB, time of the onset of

14 hatching from zona pellucida after insemination. As a control, the fertilized eggs in vitro were

15 cultured in a dish containing $50 \mu \mathrm{L}$ of $\mathrm{KSOM}$ covered with paraffin oil at $37^{\circ} \mathrm{C}$ in higher oxygen

16 tension under a humidified atmosphere in $5 \% \mathrm{CO}_{2}$ in air in a conventional $\mathrm{CO}_{2}$ incubator $\left(\mathrm{CPO}_{2}-\right.$

17 2301). The developmental stages of the embryos were observed under an inverted microscope 24

$18 \mathrm{~h}$ apart in the control group. 

to standard laboratory chow (CA-1, CLEA, Japan) and tap water. All experiments were carried out in accordance with the guidelines for the care and use of animals approved by the Obihiro

5 University of Agriculture and Veterinary Medicine. The authors confirmed that this experiment 6 complies with the ARRIVE guidelines. All animal experimental protocols were approved by the

7 Institutional Animal Ethics Committee of Obihiro University of Agriculture and Veterinary

8 Medicine. were analysed by logistic regression using the following model:

$$
\ln (\alpha / 1-\alpha)=\beta+\text { main factor (type of incubators) }
$$

where $\alpha=$ frequency of positive outcomes and $\beta=$ the intercept. The odds ratio with $95 \%$ confidence interval was calculated. Data for the timing of embryo cleavage were analysed by

14 ANOVA. Differences were considered significant at $\mathrm{P}<0.05$. All graphs were drawn using 


\section{Acknowledgements}

2 We would like to express our thanks to Fukunaga, N., Aoki, N., Kido, K., Ohashi, Y., Sanami,

3 S., and Asada, Y. for their invaluable support in the analysis of preimplantation development of

4 mouse embryos by means of a new in vitro culture system for time-lapse cinematography. We

5 would also like to thank Editage for English language editing.

6

$7 \quad$ Author contributions

8 The research was designed by H.S. and H.W. Laboratory experiments were performed by H.I.,

$9 \quad$ A.S., and H.W. The manuscript was written by H.S. and H.W.

11 Competing interests

12 The authors declare no competing interests.

14 Data availability

15 The datasets generated during and/or analysed during the current study are available from

16 the corresponding author on reasonable request.

17

18 

5

\section{References}

(

1. Whittingham, D. G. Fertilization of mouse eggs in vitro. Nature 220 592-593 (1968).

(1)

6

(

2. Iwamatsu, T. \& Chang, M. C. In vitro fertilization of mouse eggs in the presence of bovine follicular fluid. Nature 224, 919-920 (1969). 10.1038/224919a0.PMID: 5389397

\section{$\underline{10.1038 / 220592 \mathrm{a} 0}$, Pubmed: $\underline{5686738}$}

3. Toyoda, Y., Yokoyama, M. \& Hosi, T. Studies on the fertilization of mouse eggs in vitro. I. In vitro fertilization of eggs by fresh epididymal sperm. Jpn. Anim. Reprod. 16, 147-151 (1971) (in Japanese)

4. Whitten, W. K. \& Biggers, J. D. Complete development in vitro of the pre-implantation stages of the mouse in a simple chemically defined medium. J. Reprod. Fertil. 17, 399-401 (1968).

5

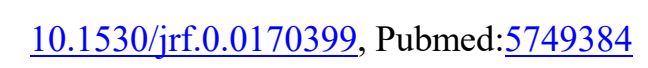

5. Abramczuk, J., Solter, D. \& Koprowski, H. The beneficial effect EDTA on development of (8) 
6. Hoshi, M. \& Toyoda, Y. Effect of EDTA on the preimplantation development of mouse embryos fertilized in vitro. Jpn J. Zootech. Sci. 56, 931-937 (1985)

7. Suzuki, H., Fukuda, Y. \& Toyoda, Y. Effect of metal-EDTA chelates on the preimplantation development of mouse embryos fertilized in vitro. J. Mamm. Ova Res. 5, 84-88 (1988)

8. Suzuki, H. \& Toyoda, Y. Normal young from in vitro fertilized mouse embryos developed in a medium supplemented with EDTA and transferred to pseudopregnant recipients. J. Mamm. Ova Res. 3, 78-85 (1986) methods. J. Reprod. Fertil. 91, 543-556 (1991). 10.1530/jrf.0.0910543, Pubmed:2013878 

mouse preimplantation embryo in chemically defined media. Biol. Reprod. 50, 1027-1033 (1994). 10.1095/biolreprod50.5.1027, Pubmed:이료

13. Biggers, J. D., McGinnis, L. K. \& Lawitts, J. A. Enhanced effect of glycyl-L-glutamine on mouse preimplantation embryos in vitro. Reprod. Biomed. Online 9, $59-69$ (2004). $\underline{10.1016 / \mathrm{s} 1472-6483(10) 62111-6, \text { Pubmed:15257821 }}$

14. Brinster, R. L. A method for in vitro cultivation of mouse ova from two-cell to blastocyst. Exp. Cell Res. 32, 205-208 (1963). 10.1016/0014-4827(63)90093-4, Pubmed:14094038 body extrusion and pronuclear formation in human oocytes using time-lapse video 
16. Mio, Y. \& Maeda, K. Time-lapse cinematography of dynamic changes occurring during in vitro development of human embryos. Am. J. Obstet. Gynecol. 199, 660.e1-660.e5 (2008). 10.1016/j.ajog.2008.07.023, Pubmed:18823872

6

17. Lundin, K., Bergh, C. \& Hardarson, T. Early embryo cleavage is a strong indicator of embryo quality in human IVF. Hum. Reprod. 16, 2652-2657 (2001). 10.1093/humrep/16.12.2652,

Pubmed: $\underline{11726590}$

18. Alikani, M. et al. Human embryo fragmentation in vitro and its implications for pregnancy and implantation. Fertil. Steril. 71, 836-842 (1999). 10.1016/s0015-0282(99)00092-8, Pubmed: $\underline{10231042}$ 
1

2

3

4

5

6

7

8

9

10

11

20. Hardarson, T. et al. Internalization of cellular fragments in a human embryo: time-lapse recordings. Reprod. Biomed. Online. 5, 36-38 (2001).

21. Van Blerkom, J., Davis, P. \& Alexander, S. A microscopic and biochemical study of fragmentation phenotypes in stage-appropriate human embryos. Hum. Reprod. 16, 719-729 (2001). 10.1093/humrep/16.4.719, Pubmed:11278225

22. Iwata, K. et al. Analysis of compaction initiation in human embryos by using time-lapse cinematography. J. Assist. Reprod. Genet. 31, 421-426 (2014). 10.1007/s10815-014-0195-2, Pubmed:24610095

23. Mizobe, Y. et al. Selection of human blastocysts with a high implantation potential based on timely compaction. J. Assist. Reprod. Genet. 34, 991-997 (2017). 10.1007/s10815-017-0962y, Pubmed:28573523

24. Zhang, J. et al. Using time-lapse technology to explore vacuolization in embryos on Day 3 and Day 4. Arch. Gynecol. Obstet. 299, 857-862 (2019). 10.1007/s00404-018-5008-x, Pubmed:30569342 
25. Rienzi, L. et al. Time of morulation and trophectoderm quality are predictors of a live birth after euploid blastocyst transfer: a multicenter study. Fertil. Steril. 112, 1080-1093.e1 (2019)

26. Harada, Y. et al. Selection of high-quality and viable blastocysts based on timing of morula compaction and blastocyst formation. Reprod. Med. Biol. 19, 58-64 (2020).

27. Lagalla, C. et al. Alternative patterns of partial embryo compaction: prevalence, morphokinetic history and possible implications. Reprod. Biomed. Online 40, 347-354 (2020). 10.1016/j.rbmo.2019.11.011, Pubmed:32057674

28. Gardner, D. K. et al. A prospective randomized trial of blastocyst culture and transfer in invitro fertilization. Hum. Reprod. 13, 3434-3440 (1998). 10.1093/humrep/13.12.3434, Pubmed: 9886530 
human blastocyst: optimal inner cell mass size and shape. Fertil. Steril. 76, 1157-1167 (2001).

30. Salumets, A. et al. Early cleavage predicts the viability of human embryos in elective single embryo transfer procedures. Hum. Reprod. 18, 821-825 (2003). 10.1093/humrep/deg184, Pubmed: $\underline{12660278}$

31. Giorgetti, C. et al. Early cleavage: an additional predictor of high implantation rate following elective single embryo transfer. Reprod. Biomed. Online_14, 85-91 (2007). 10.1016/s14726483(10)60768-7, Pubmed: $\underline{17207338}$

32. Lechniak, D., Pers-Kamczyc, E. \& Pawlak, P. Timing of the first zygotic cleavage as a marker of developmental potential of mammalian embryos. Reprod. Biol. 8, 23-42 (2008). $\underline{10.1016 / \mathrm{s} 1642-431 \mathrm{x}(12) 60002-3}$, Pubmed: 18432305

33. Meseguer, M. et al. Embryo incubation and selection in a time-lapse monitoring system improves pregnancy outcome compared with a standard incubator: a retrospective cohort study. Fertil. Steril. 98, 1481-9.e10 (2012). 10.1016/j.fertnstert.2012.08.016, 
34. Wu, L. et al. Embryo culture using a time-lapse monitoring system improves live birth rates compared with a conventional culture system: a prospective cohort study. Hum. Fertil. (Camb) 21, 255-262 (2018). 10.1080/14647273.2017.1335886, Pubmed:28597711

6

35. Pribenszky, C. et al. Prediction of in-vitro developmental competence of early cleavage-stage mouse embryos with compact time-lapse equipment. Reprod. Biomed. Online 20, 371-379 (2010). 10.1016/j.rbmo.2009.12.007, Pubmed:20089456

36. Kim, J., Kim, S. H. \& Jun, J. H. Prediction of blastocyst development and implantation potential in utero based on the third cleavage and compaction times in mouse pre-implantation embryos. J._Reprod._Dev. 63, 117-125 (2017). 10.1262/jrd.2016-129, Pubmed:27980237 role of oriented division during fourth cleavage. Dev. Biol. 137, $13-25$ (1990). 10.1016/0012- 
38. Ajduk, A., Yamauchi, Y. \& Ward, M. A. Sperm chromatin remodeling after intracytoplasmic sperm injection differs from that of in vitro fertilization. Biol. Reprod. 75, 442-451 (2006). $\underline{\text { 10.1095/biolreprod.106.053223, Pubmed: } 16775225}$

39. Rubio, I. et al. Clinical validation of embryo culture and selection by morphokinetic analysis: a randomized, controlled trial of the embryoscope. Fertil. Steril. 102, 1287-1294.e5 (2014). $\underline{10.1016 / j . f e r t n s t e r t .2014 .07 .738, ~ P u b m e d: 25217875 ~}$

40. Pribenszky, C., Nilselid, A. M. \& Montag, M. Time-lapse culture with morphokinetic embryo selection improves pregnancy and live birth chances and reduces early pregnancy loss: a meta-analysis. Reprod. Biomed. Online 35, 511-520 (2017). 10.1016/j.rbmo.2017.06.022, Pubmed:28736152

41. Mori, C. et al. Advantage of dry culture system for human embryo culture in Assisted Reproductive Technology (ART). J. Clin. Embryologist 13, 39-42. in Japanese (2011)

42. Karnaukhov, A. V. et al. Time-lapse cinematography study of preimplantation mouse embryo development. Dokl. Biol. Sci. 426, 306-310 (2009). 10.1134/s001249660903034x, 
Pubmed:19650347

43. Leung, C. Y., Zhu, M. \& Zernicka-Goetz, M. Polarity in cell-fate acquisition in the early mouse embryo. Curr. Top. Dev. Biol. 120, 203-234 (2016). 10.1016/bs.ctdb.2016.04.008, Pubmed:27475853

44. Coticchio, G., Lagalla, C., Sturmey, R., Pennetta, F. \& Borini, A. The enigmatic morula: mechanisms of development, cell fate determination, self-correction and implications for ART. Hum. Reprod. Update 25, 422-438 (2019). 10.1093/humupd/dmz008, Pubmed: $\underline{30855681}$

45. Zheng, Z., Li, H., Zhang, Q., Yang, L. \& Qi, H. Unequal distribution of 16 S mtrRNA at the 2-cell stage regulates cell lineage allocations in mouse embryos. Reproduction 151, 351-367 (2016). 10.1530/REP-15-0301, Pubmed:26762401

46. Burton, A. et al. Single-cell profiling of epigenetic modifiers identifies PRDM14 as an inducer of cell fate in the mammalian embryo. Cell Rep. 5, 687-701 (2013). 10.1016/j.celrep.2013.09.044, Pubmed:24183668

47. Goolam, M. et al. Heterogeneity in Oct4 and Sox2 targets biases cell fate in 4-cell 
48. Hardarson, T. et al. Internalization of cellular fragments in a human embryo: time-lapse recordings. Reprod. Biomed. Online 5, 36-38 (2002). 10.1016/s1472-6483(10)61594-5, Pubmed: 12470543

6

49. Tamaki, T. et al. Impact of an improvement of procedure of embryo culture for reducing the times of opening of the door of incubator on the fertilization rate and embryo development.

10

11

12

13

14

15

16

17 


\section{Figure legends}

2

3

Fig. 1. Histogram of the number of embryos fertilised in vitro at each developmental stage with the lapse of time after insemination. Embryos cultured in higher oxygen tension and lower oxygen tension in CCM-iBIS are indicated in black and white, respectively. Values show the range of time to cleavage in each developmental stage. Cleavage and development of embryos fertilised in vitro were much more synchronised in lower oxygen tension than in higher oxygen tension in CCM-iBIS. Parameters regarding embryonic development are annotated as follows: t2, time of cleavage to the 2-cell stage after insemination; $\mathbf{t} 3$, time of cleavage to the 3 -cell stage after insemination; $\mathrm{t} 4$, time of cleavage to the 4-cell stage after insemination; $\mathrm{t} 5$, time of cleavage to the 5-cell stage after insemination; tOC, time of the onset of compaction after insemination; tM, time of formation of fully compacted morula after insemination; tB, time of formation of blastocyst with blastocoel at half volume of the embryo after insemination.

Fig. 2. Timing of cleavage of mouse in vitro fertilised embryos during preimplantation development cultured in lower oxygen tension in a non-humidifying incubator with time-lapse cinematography (CCM-iBIS).

Fig. 3. Relationship between attainment time to 2-cell, 3-cell, 4-cell, 5-cell, initiation of 
1 compaction and morula, and attainment time to blastocyst stage.

2 
Table 1. Results of in vitro cultivation of mouse embryos fertilized in vitro under high and low oxygen tension in a non-humidifying incubator with time-lapse cinematography (CCM-iBIS)

\begin{tabular}{|c|c|c|c|c|c|c|}
\hline \multirow{3}{*}{ Incubator } & \multirow{3}{*}{$\begin{array}{l}\text { No. of } \\
\text { fertilized eggs } \\
\text { cultured }\end{array}$} & \multicolumn{5}{|c|}{ No. (\%) of development to: } \\
\hline & & \multirow{2}{*}{$\begin{array}{c}2 \text {-cell } \\
(24 \mathrm{hr})^{1}\end{array}$} & \multirow{2}{*}{$\begin{array}{c}\text { 4-cell } \\
(48 \mathrm{hr})^{1}\end{array}$} & \multirow{2}{*}{$\begin{array}{l}\text { Morula } \\
(72 \mathrm{hr})^{1}\end{array}$} & \multicolumn{2}{|c|}{ Blastocyst } \\
\hline & & & & & $(96 \mathrm{hr})^{1}$ & $(120 \mathrm{hr})^{1}$ \\
\hline $\begin{array}{l}\mathrm{CPO}_{2}-2301^{2} \\
\left(5 \% \mathrm{CO}_{2} \text { in air }\right)\end{array}$ & 100 & $96 \quad(96.0)^{\mathrm{a}}$ & $79(79.0)^{\mathrm{a}}$ & $71 \quad(71.0)^{\mathrm{ab}}$ & $84(84.0)^{\mathrm{a}}$ & $86(86.0)^{\mathrm{a}}$ \\
\hline $\begin{array}{l}\text { CCM-iBIS }{ }^{3} \\
\left(5 \% \mathrm{CO}_{2} \text { in air }\right)\end{array}$ & 951 & $940 \quad(98.8)^{\mathrm{a}}$ & $845(88.9)^{b}$ & $588(61.8)^{\mathrm{a}}$ & $733(77.1)^{\mathrm{a}}$ & $835(87.8)^{\mathrm{a}}$ \\
\hline $\begin{array}{l}\mathrm{CCM}-\mathrm{iBIS}^{3} \\
\left(5 \% \mathrm{CO}_{2}, 5 \% \mathrm{O}_{2}\right. \\
\left.90 \% \mathrm{~N}_{2}\right)\end{array}$ & 297 & $292(98.3)^{\mathrm{a}}$ & $288(97.0)^{\mathrm{c}}$ & $215(72.4)^{b}$ & $280(94.3)^{b}$ & $288(97.0)^{b}$ \\
\hline
\end{tabular}


Table 2. Developmental stage of in vitro fertilized mouse embryos at every $24 \mathrm{hr}$ after insemination.

\begin{tabular}{|c|c|c|c|c|c|c|c|c|c|c|c|c|c|}
\hline \multirow{2}{*}{ Incubator } & \multicolumn{3}{|c|}{$24 \mathrm{hr}^{1}$} & \multicolumn{2}{|c|}{$48 \mathrm{hr}^{1}$} & \multicolumn{2}{|c|}{$72 \mathrm{hr}^{1}$} & \multicolumn{3}{|c|}{$96 \mathrm{hr}^{1}$} & \multicolumn{3}{|c|}{$120 \mathrm{hr}^{1}$} \\
\hline & 2-cell & 3 -cell & 4-cell & 4-cell & 5-cell & Com & Morula & BL & ExBL & H-BL & BL & ExBL & H-BL \\
\hline $\begin{array}{l}\mathrm{CPO}_{2}-2301^{2} \\
\text { (high } \mathrm{O}_{2} \text { tension) }\end{array}$ & $\begin{array}{c}96 \\
(100)\end{array}$ & $\begin{array}{c}0 \\
(0.0)\end{array}$ & $\begin{array}{c}0 \\
(0.0)\end{array}$ & $\begin{array}{c}76 \\
(96.2)\end{array}$ & $\begin{array}{c}3 \\
(3.8)\end{array}$ & \multicolumn{2}{|c|}{$\begin{array}{c}71 \\
(100)^{4}\end{array}$} & $\begin{array}{c}56 \\
(66.7)\end{array}$ & $\begin{array}{c}24 \\
(28.6)\end{array}$ & $\begin{array}{c}4 \\
(4.8)\end{array}$ & $\begin{array}{c}6 \\
(7.0)\end{array}$ & $\begin{array}{c}15 \\
(17.4)\end{array}$ & $\begin{array}{c}65 \\
(75.6)\end{array}$ \\
\hline $\begin{array}{l}\text { CCM-iBIS } \\
\text { (high } \mathrm{O}_{2} \text { tension) }\end{array}$ & $\begin{array}{c}939 \\
(99.9)\end{array}$ & $\begin{array}{c}0 \\
(0.0)\end{array}$ & $\begin{array}{c}1 \\
(0.1)\end{array}$ & $\begin{array}{c}761 \\
(90.1)\end{array}$ & $\begin{array}{c}84 \\
(9.9)\end{array}$ & $\begin{array}{c}292 \\
(33.2)\end{array}$ & $\begin{array}{c}588 \\
(66.8)\end{array}$ & $\begin{array}{c}262 \\
(35.7)\end{array}$ & $\begin{array}{c}45 \\
(6.1)\end{array}$ & $\begin{array}{c}426 \\
(58.1)\end{array}$ & $\begin{array}{c}145 \\
(17.4)\end{array}$ & $\begin{array}{c}68 \\
(8.1)\end{array}$ & $\begin{array}{c}622 \\
(74.5)\end{array}$ \\
\hline $\begin{array}{l}\text { CCM-iBIS }{ }^{3} \\
\text { (low } \mathrm{O}_{2} \text { tension) }\end{array}$ & $\begin{array}{c}291 \\
(99.7)\end{array}$ & $\begin{array}{c}1 \\
(0.3)\end{array}$ & $\begin{array}{c}0 \\
(0.0)\end{array}$ & $\begin{array}{c}178 \\
(61.8)\end{array}$ & $\begin{array}{c}110 \\
(38.2)\end{array}$ & $\begin{array}{c}75 \\
(25.9)\end{array}$ & $\begin{array}{c}215 \\
(74.1)\end{array}$ & $\begin{array}{c}12 \\
(4.3)\end{array}$ & $\begin{array}{c}147 \\
(52.5)\end{array}$ & $\begin{array}{c}121 \\
(43.2)\end{array}$ & $\begin{array}{c}4 \\
(1.4)\end{array}$ & $\begin{array}{c}143 \\
(49.7)\end{array}$ & $\begin{array}{c}141 \\
(49.0)\end{array}$ \\
\hline
\end{tabular}

${ }^{1}$ Hours after insemination. Com: Initiation of compaction, BL: Blastocyst, ExBL: Expanded Blastocyst, H-BL: Hatching Blastocyst.

${ }^{2}$ Humidifying conventional $\mathrm{CO}_{2}$ incubator.

${ }^{3}$ Non-humidifying incubator with time-lapse cinematography.

${ }^{4}$ These embryos ("compacting" or "compacted" morula) were indistinguishable. 
Table 3. Results of attainment time after insemination to each developmental stage of in vitro fertilized mouse embryos cultured under high and low oxygen tension in CCM-iBIS

\begin{tabular}{|c|c|c|c|c|c|c|c|}
\hline \multirow[b]{2}{*}{ Incubator } & \multicolumn{7}{|c|}{ Hours after insemination ${ }^{1}$} \\
\hline & 2-cell (t2) & 3-cell (t3) & 4-cell (t4) & 5 -cell (t5) & $\begin{array}{c}\text { Onset of } \\
\text { compaction } \\
\text { (tOC) }\end{array}$ & Morula (tM) & Blastocyst (tB) \\
\hline $\begin{array}{l}\text { CCM-iBIS }{ }^{2} \\
\text { (high } \mathrm{O}_{2} \text { tension) }\end{array}$ & $17.63 \pm 0.04^{\mathrm{a}}$ & $39.83 \pm 0.09^{\mathrm{a}}$ & $41.17 \pm 0.12^{\mathrm{a}}$ & $51.97 \pm 0.13^{\mathrm{a}}$ & $59.37 \pm 0.14^{\mathrm{a}}$ & $69.54 \pm 0.18^{\mathrm{a}}$ & $85.99 \pm 0.29^{a}$ \\
\hline $\begin{array}{l}\text { CCM-iBIS }{ }^{2} \\
\text { (low } \mathrm{O}_{2} \text { tension) }\end{array}$ & $17.45 \pm 0.07^{\mathrm{b}}$ & $38.66 \pm 0.13^{b}$ & $39.63 \pm 0.15^{b}$ & $49.04 \pm 0.17^{b}$ & $57.66 \pm 0.19^{b}$ & $70.01 \pm 0.22^{\mathrm{a}}$ & $82.35 \pm 0.27^{b}$ \\
\hline
\end{tabular}

${ }^{1}$ Data are shown as mean \pm SEM in decimal. The embryos developed to the blastocyst stage within $120 \mathrm{hr}$ after insemination were used for calculation (range: $n=839-842$ and $n=280-289$ in $20 \%$ and $5 \% \mathrm{O}_{2}$, respectively).

${ }^{2}$ Non-humidifying incubator with time-lapse cinematography.

a-b: Values with different superscripts are significantly different in the same column at $\mathrm{P}<0.05$. 
Table 4. Results of in vitro cultivation of mouse embryos fertilized in vitro in a non-humidifying incubator with time-lapse cinematography (CCM-iBIS) and a humidifying conventional $\mathrm{CO}_{2}$ incubator $\left(\mathrm{CPO}_{2}-2301\right)$ without handling of culturing embryos inside and outside the incubator.

\begin{tabular}{|c|c|c|c|}
\hline \multirow[b]{2}{*}{ Incubator } & \multirow{2}{*}{$\begin{array}{c}\text { No. of } \\
\text { fertilized eggs } \\
\text { cultured }\end{array}$} & \multicolumn{2}{|c|}{ No. $(\%)$ of development to: } \\
\hline & & $\begin{array}{c}\text { 4-cell } \\
(48 \mathrm{hr})^{1}\end{array}$ & $\begin{array}{c}\text { Blastocyst } \\
\text { (96 hr) }^{1}\end{array}$ \\
\hline \multirow[t]{2}{*}{$\mathrm{CPO}_{2}-2301^{2}$} & 50 & $42(84.0)^{\mathrm{a}}$ & - \\
\hline & 50 & - & $41 \quad(82.0)^{\mathrm{a}}$ \\
\hline $\mathrm{CCM}_{-1 B I S}{ }^{3,4}$ & 951 & $845(88.9)^{a}$ & $733(77.1)^{\mathrm{a}}$ \\
\hline
\end{tabular}

\footnotetext{
${ }^{1}$ Hours after insemination.

${ }^{2}$ Humidifying conventional $\mathrm{CO}_{2}$ incubator at $37^{\circ} \mathrm{C}, 5 \% \mathrm{CO}_{2}$ in air.

${ }^{3}$ Non-humidifying incubator with time-lapse cinematography at $37^{\circ} \mathrm{C}, 5 \% \mathrm{CO}_{2}$ in air.

${ }^{4}$ Data are from Table 1.

Values with the same superscripts are not significantly different in the same column at $\mathrm{P}<0.05$.
} 
Figures

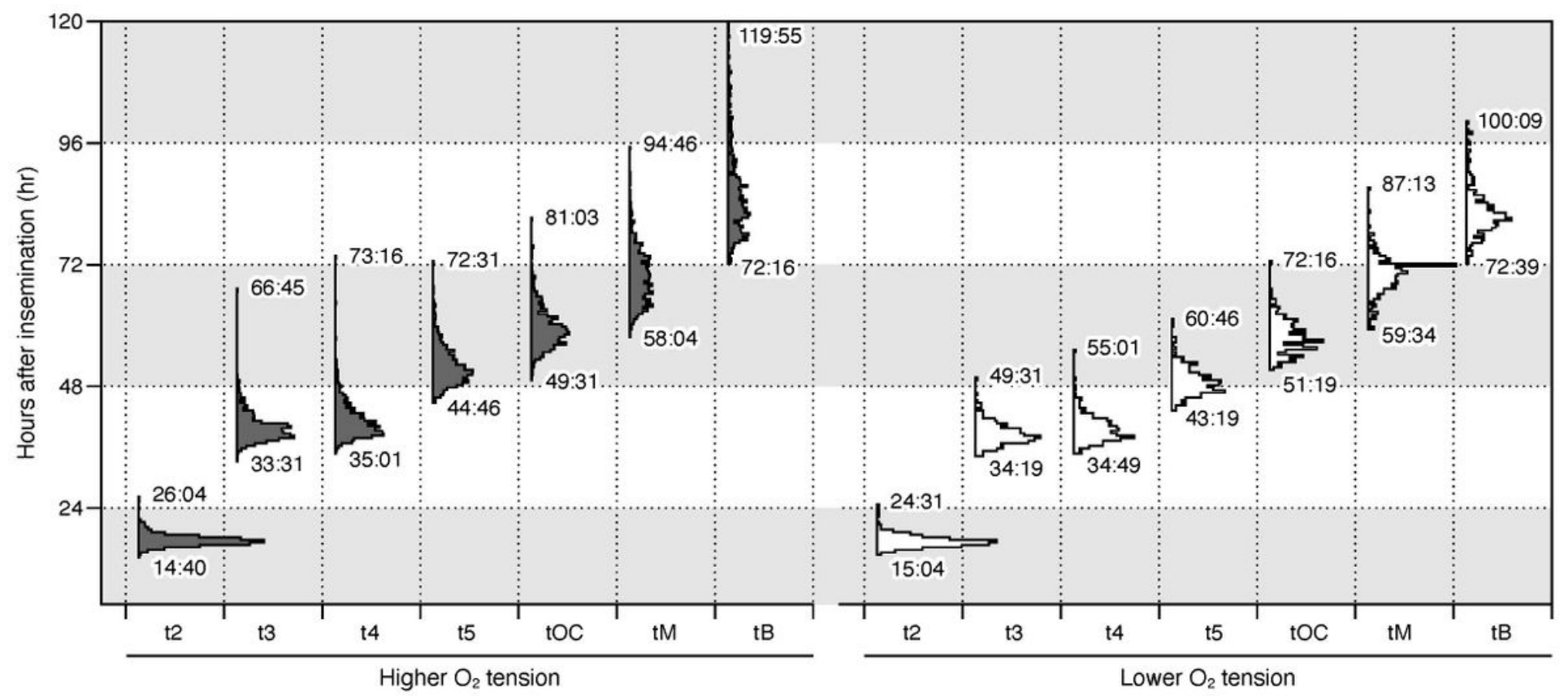

Figure 1

Histogram of the number of embryos fertilised in vitro at each developmental stage with the lapse of time after insemination. Embryos cultured in higher oxygen tension and lower oxygen tension in CCM-iBIS are indicated in black and white, respectively. Values show the range of time to cleavage in each developmental stage. Cleavage and development of embryos fertilised in vitro were much more synchronised in lower oxygen tension than in higher oxygen tension in CCM-iBIS. Parameters regarding embryonic development are annotated as follows: $t 2$, time of cleavage to the 2-cell stage after insemination; $\mathrm{t} 3$, time of cleavage to the 3 -cell stage after insemination; $t 4$, time of cleavage to the 4-cell stage after insemination; $t 5$, time of cleavage to the 5-cell stage after insemination; tOC, time of the onset of compaction after insemination; $\mathrm{tM}$, time of formation of fully compacted morula after insemination; $\mathrm{t} B$, time of formation of blastocyst with blastocoel at half volume of the embryo after insemination. 

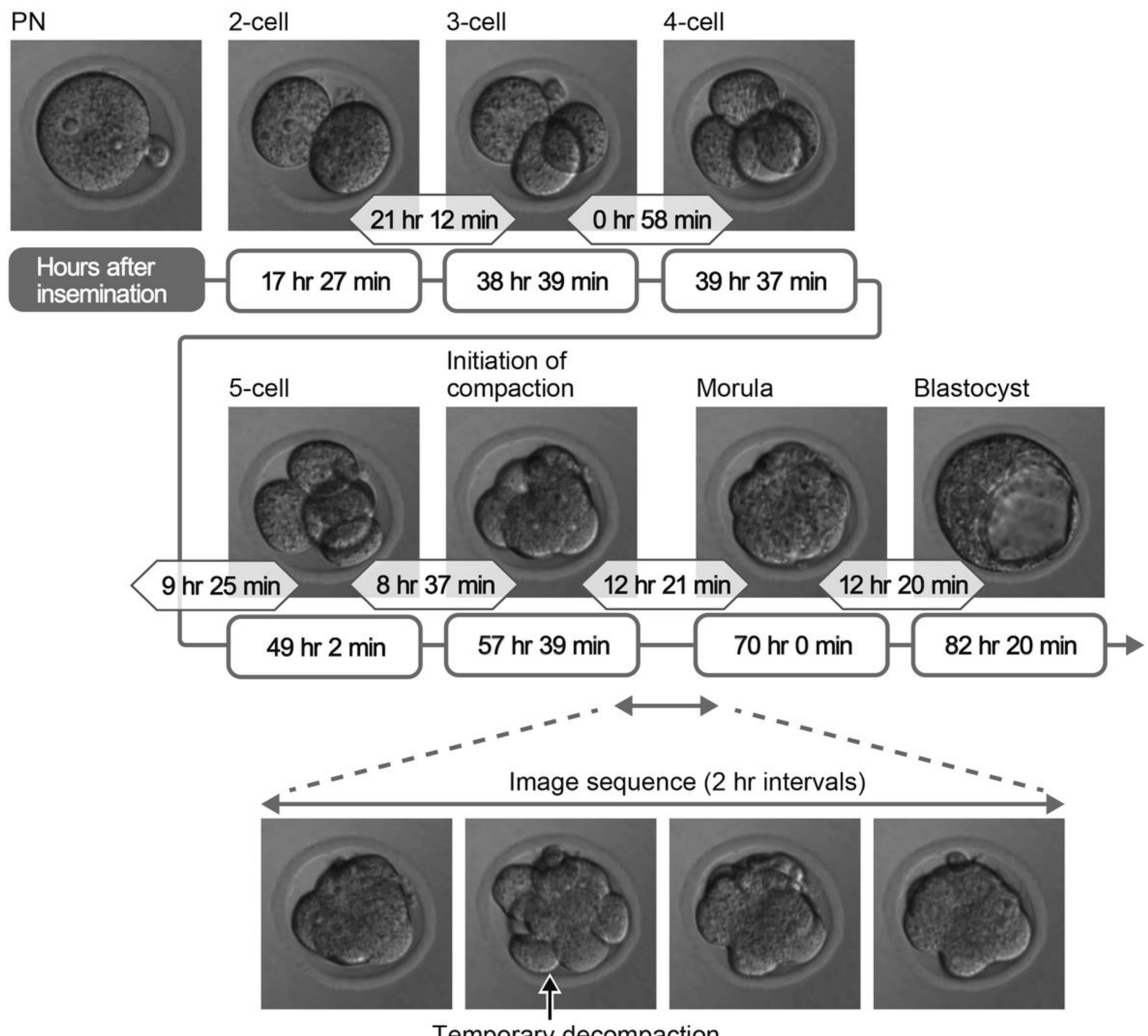

Temporary decompaction

Figure 2

Timing of cleavage of mouse in vitro fertilised embryos during preimplantation development cultured in lower oxygen tension in a non-humidifying incubator with time-lapse cinematography (CCM-iBIS). 


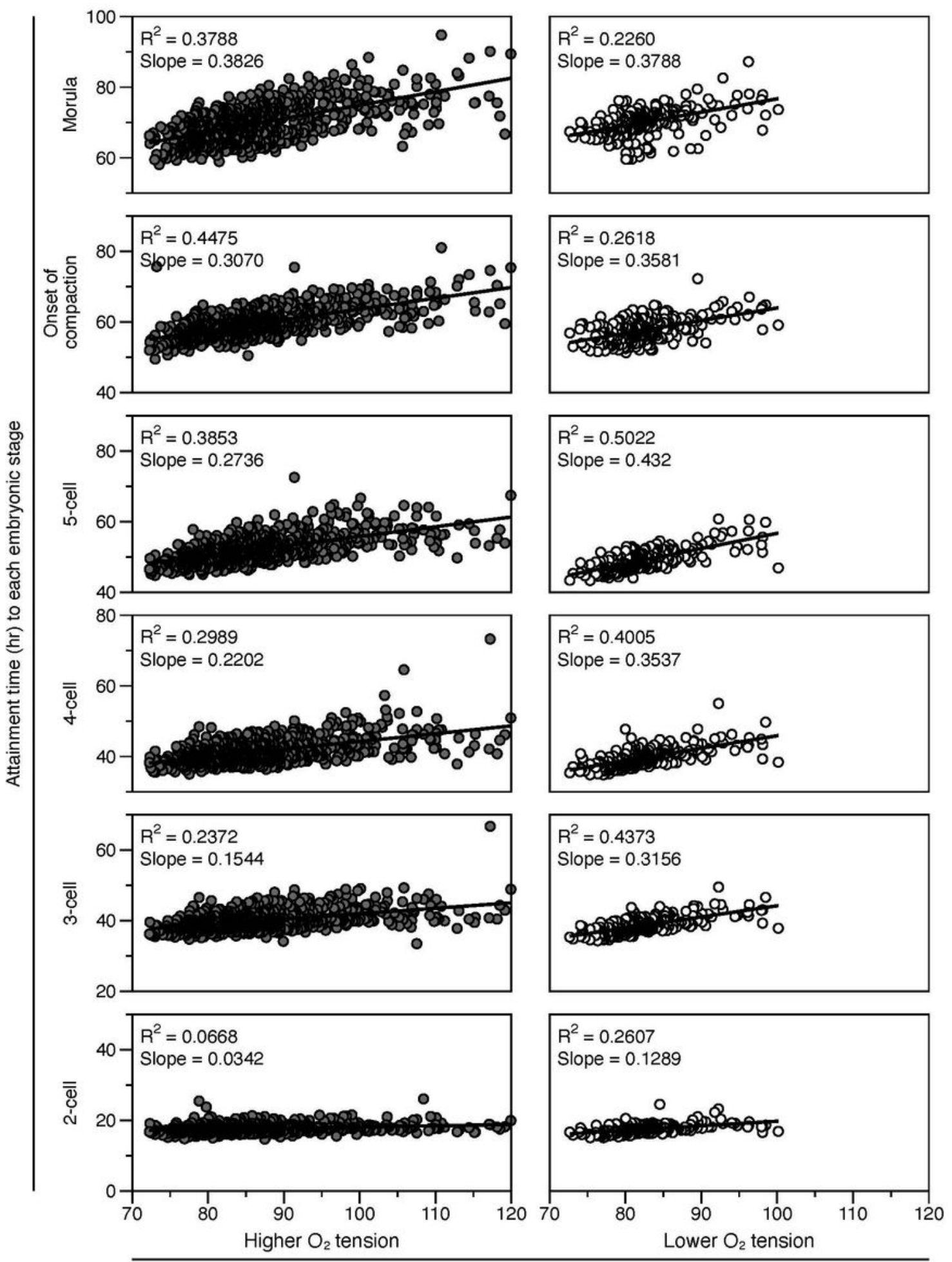

Attainment time (hr) to blastocyst stage

\section{Figure 3}

Relationship between attainment time to 2-cell, 3-cell, 4-cell, 5-cell, initiation of compaction and morula, and attainment time to blastocyst stage. 